\title{
BDS: AJUDA OU PREJUDICA O MOVIMENTO PALESTINO?
}

Daniella Köhnen Abramovay ${ }^{1}$

Em 9 de julho de 2005, representantes da sociedade civil palestina lançaram uma campanha de boicote, desinvestimento e sanções (BDS) a fim de protestar de forma não violenta contra a situação dos palestinos nos territórios ocupados, em Israel e no exterior. O BDS alega pretender unificar o povo palestino em sua luta por autodeterminação, justiça, igualdade e liberdade por meio do boicote econômico, cultural e acadêmico a Israel.

Inspirado pelo movimento contra o apartheid na África do Sul, o BDS surgiu como resposta aos constantes fracassos da sociedade internacional de penalizar Israel por suas violações de direito internacional, sobretudo, pela falta de implementação de resoluções da ONU, de forma semelhante a sanções. Desde 2008, o BDS é comandado pelo Comitê Nacional do BDS (BDSNC).

Omar Barghouti, um dos seus principais formuladores, argumenta que o movimento pretende alcançar três objetivos: o fim da ocupação israelense pós-1967 e a derrubada do muro que separa os territórios ocupados de Israel; o estabelecimento de igualdade jurídica entre palestinos cidadãos de Israel e israelenses; e o direito de retorno de todos refugiados palestinos às suas moradias originais. ${ }^{2}$

0 apoio ao BDS expandiu-se substancialmente nos últimos anos, principalmente depois da incursão militar israelense na faixa de Gaza em 2008 e do episódio da flotilha em 2010, que prejudicaram a imagem de Israel perante à sociedade internacional. Da

\footnotetext{
1 Pesquisadora, formada em História pela Universidade de São Paulo e Relações Internacionais pela Pontifícia Universidade Católica de São Paulo. Atualmente, faz pós-graduação em Global Affairs na New York University (NYU).

2 BARGHOUTI, Omar. BDS: Boycott, Divestment, Sanctions: the global struggle for palestinian rights. Haymarket Books, Chicago, Illinois. 2011. p.49.
} 
mesma forma, a falta de crença na possibilidade de uma solução duradoura para o conflito israelo-palestino resultou em mais adeptos.

O BDS tem o apoio de certas ONG, partidos políticos, associações de direitos dos refugiados, sindicatos, acadêmicos, empresários e igrejas, da Palestina e de outros países. Algumas organizações israelenses também juntaram-se ao movimento, entre elas, o "Boycott! Supporting the Palestinian BDS from whithin", "The Alternative Information Center" (AIC), "The Israeli Committee Against House Demolition” (ICAHD) e "Who profits from the occupation?"

O movimento atua com vistas a boicotar todos os produtos e serviços provenientes de Israel - e não apenas os dos territórios ocupados-, assim como todas as instituições culturais e acadêmicas do país. ${ }^{3}$ Alguns dos boicotes atualmente implementados, entretanto, não podem ser automaticamente vinculados ao movimento BDS, porque limitam-se apenas às atividades econômicas associadas aos assentamentos e não a todos produtos e serviços israelenses.

Sindicatos no Reino Unido, Irlanda e África do Sul, por exemplo, aprovaram legislação para retirar investimentos em empresas que lucram com a ocupação dos territórios palestinos. Empresas que fornecem equipamentos e serviços militares para Israel (Caterpillar, United Technologies, General Eletric, ITT, Terex) que são, eventualmente, usadas nos assentamentos, são igualmente objeto de boicote; assim como a marca de cosméticos AHADA, cuja fábrica se situa na Cisjordânia.

No tocante ao boicote cultural e acadêmico, a PACBI (Palestinian Campaign for the Academic and Cultural Boycott of Israel), também criada por Omar Barghouti, inspirou a criação nos Estados Unidos da USACBI (United States Academic and Cultural Boycott of Israel) e de semelhantes grupos no Canadá, Itália, Espanha e França. O boicote concentra sua atenção, principalmente, em eventos culturais que tenham a participação de artistas israelenses, no entanto, em alguns países também incorpora restrições culturais a filmes e música provenientes de Israel.

Recentemente, o movimento a favor do boicote começou a atrair a atenção de importantes instituições financeiras mundiais. Na Holanda, o fundo de pensões PGGM retirou recursos investidos em cinco instituições financeiras israelenses; e a empresa Vitens, de canalização de água, suspendeu negócios com a homóloga israelense Mekorot.

\footnotetext{
3 BARGHOUTI, Omar. BDS: Boycott, Divestment, Sanctions: the global struggle for palestinian rights. Haymarket Books, Chicago, Illinois. 2011. p.49.
} 
O banco dinamarquês Danske, por sua vez, removeu, no início de 2014, investimentos junto ao banco israelense Hapoalim, que financia a construção de assentamentos em territórios ocupados. O Ministério das Finanças norueguês, igualmente, instituiu proibição de que recursos do fundo do petróleo destinem-se a empresas israelenses envolvidas com a ocupação. Similarmente, a Alemanha interrompeu a concessão de financiamento à pesquisa para empresas israelenses de alta tecnologia localizadas nos territórios palestinos ocupados.

Concomitantemente, os países europeus negociam a adoção de rotulagem diferenciada para produtos provenientes dos territórios palestinos ocupados (TPO), que, com isso, não seriam mais beneficiados pelas tarifas preferenciais vigentes no acordo firmado entre União Europeia e Israel em 2000. Da mesma forma, a sociedade civil europeia, por meio da campanha "Quem lucra?", tenciona mostrar o seu endosso à diferenciação dos produtos. A rotulagem diferenciada já foi implementada no Reino Unido e na Dinamarca. No Brasil, o acordo firmado entre Israel e o MERCOSUL contém cláusula relativa à proibição de importação de bens produzidos nos territórios palestinos ocupados, na Cisjordânia e em Jerusalém Oriental. Para que sua autenticidade seja verificada, os produtos devem vir acompanhados de um Certificado de Origem.

A despeito do fato de o boicote não apresentar considerável impacto imediato na economia israelense, analistas consideram que, no longo prazo, a continuidade da política de assentamentos e a intensificação do boicote poderia ameaçar a economia israelense, pela potencial repercussão sobre ampla gama de setores e empresas, sobretudo de alta tecnologia. 0 ministro de finanças de Israel, Yair Lapid, admite que, se as ações de boicote forem aderidas em grande escala, principalmente por europeus, causarão danos irreparáveis à economia israelense, gerando desemprego e diminuição significativa do comércio.

Mais do que causar dano econômico a Israel, os boicotes tiveram êxito em desafiar a autoridade moral de Israel ao colocar em evidência a falta de legitimidade dos ganhos econômicos resultantes da ocupação. Um novo tipo de ameaça emergiu, o da deslegitimação do Estado de Israel que, se não tratada a tempo, pode tornar-se ainda mais prejudicial do que a militar. Tendo isso em vista, organizações judaicas na Europa e nos Estados Unidos atuam a fim de evitar prejuízos maiores à imagem do Estado de Israel. Nos Estados Unidos, o "Israel Action Network" pode ser visto como o mais ambicioso deles. Ademais, o país implementou uma política ativa de promoção literária, 
cultural e artística, a fim de mostrar para a sociedade internacional que Israel não se resume apenas à ocupação, religião e conflito. Com o mesmo fim, agem seu corpo diplomático e a comunidade judaica da diáspora. ${ }^{4}$

O maior êxito da campanha do BDS - que inspirou outros boicotes - relaciona-se com a exposição internacional da situação dos palestinos em Israel: a realidade da ocupação, a desigualdade de direitos e o desejo de retorno dos refugiados. Como o governo israelense é alvo de extensas críticas por parte da sociedade internacional pelo fato de proteger e promover os interesses dos colonos nos territórios palestinos ocupados, é compreensível a estratégia do BDS de não diferenciar o governo de Israel supostamente representante da sociedade - dos colonos. Segundo essa lógica, prejudicar Israel é a única forma de forçar uma mudança na política de assentamentos.

O movimento, no entanto, teria mais sucesso se objetivasse prejudicar apenas as empresas diretamente envolvidas com a indústria dos assentamentos ou que operem nos TPOs. Dessa forma, o boicote seria capaz de obstruir a fonte de renda dessas empresas ou ao menos prejudicar sua imagem, com o fim de inviabilizá-las comercialmente, obrigando-as a retirarem-se dos territórios palestinos ocupados.

Ao atuar indiscriminadamente contra todas as empresas israelenses, o BDS desconsidera o fato de que muitas dessas empresas - tais como a Sodastream, que recentemente fechou a sua filial na Cisjordânia- representam oportunidades de trabalho para palestinos, em alguns casos inclusive com salários e direitos semelhantes aos seus homólogos israelenses.

Nesse sentido, embora seus ideais possam ser considerados nobres, sua forma de alcançá-los é passível de questionamento. Ao invés de focar nas ações ilegais do governo israelense, sobretudo nos assentamentos, o movimento questiona aspectos ideológicos do conflito como o projeto sionista, a legitimidade de Israel e a sua caracterização como Estado judaico. Em vez de adotar medidas pontuais contra as injustiças da ocupação, o BDS promove boicote a Israel e não aos produtos dos territórios palestinos ocupados. Pretende deslegitimar a política israelense em relação aos palestinos alvejando os produtos de todo o país e sua sociedade.

Além disso, a adoção de boicote cultural e acadêmico pelo BDS extrapola os propósitos construtivos que o movimento possa ter, uma vez que cerceia a liberdade acadêmica e a circulação de idéias e opiniões, que são parte integral de uma sociedade

\footnotetext{
${ }^{4}$ Sanctions against Israel: a campaign that is gathering weight. The Economist. 08/12/2014.
} 
internacional livre e democrática. 0 boicote a professores e pesquisadores restringe sua habilidade acadêmica e prejudica a continuidade de uma atmosfera educada e crítica e, portanto, obstrui a existência de qualquer debate intelectual sobre o tema. 0 movimento prejudica, assim, a maior vitória da cultura e da academia, que é o fato de conseguirem situar-se acima de questões políticas.

Apesar de o BDS não assumir oficialmente posição quanto à solução do conflito israelo-palestino, fica claro que o atendimento à sua terceira demanda, a do direito de retorno, só pode ser conseguido dentro de um Estado binacional, secular e democrático. O movimento, portanto, sutilmente, clama pelo fim de Israel como Estado judaico, já que a volta dos refugiados -e seus descendentes que somam milhões- comprometeria a identidade judaica de Israel, onde os judeus tornar-se-iam minoria. A evocação do direito de retorno dos refugiados palestinos afasta o BDS dos grupos que se dedicam, por décadas, a implementar a solução de dois Estados. Organizações judaicas nos Estados Unidos, como J Street e Aipac argumentam que o movimento não distingue claramente sua oposição à ocupação pós-1967 do direito de Israel de existir como um Estado judaico. Organizações árabe-americanas, como "American Task Force on Palestine", igualmente, opõem-se ao BDS, pois veem a proposta do grupo como ato de repúdio ao projeto de dois Estados como solução do conflito.

Mesmo algumas ONGs palestinas tardaram a fornecer seu apoio ao BDS, porque viam a abrangente abordagem dos direitos dos palestinos como apoio velado à solução de um Estado e, portanto, contrária ao que prega o movimento de libertação palestino desde 1980, acordado nos processos de paz da década de 1990. A Autoridade Palestina, por sua vez, nunca expressou seu apoio ao grupo. Preferiu, ao contrário, lançar o seu próprio boicote destinado apenas aos produtos provenientes dos assentamentos. ${ }^{5}$

Por essas razões, a comparação entre o BDS e o antiapartheid na África do Sul não se sustenta. Este visava somente a liberação e a emancipação da maioria da população do país, enquanto a linguagem humanista e democrática do movimento BDS acaba entrando em contradição com posturas que se revelam discriminatórias.

A história mostrou a necessidade da existência de um Estado judaico. Para que ele continue a existir como um Estado democrático e promotor dos direitos humanos, contudo, o país precisa por fim à corrosiva ocupação e à indústria a ela associada. 0 5 http://blogs.telegraph.co.uk/news/jakewallissimons/100275416/israels-enemies-are-dealt-a-heavy-
blow-by-the-palestinian-authority/. 
boicote é um instrumento legítimo, mas para ser justo e eficaz não deveria extrapolar a punição das atividades econômicas dos territórios ocupados. Acima de tudo, Israel precisa comprometer-se com a solução dos dois Estados para o fim do conflito com os palestinos. Dada a expansão da campanha de deslegitimação, o fim do conflito - e a implementação de uma duradoura paz - nunca se mostrou tão urgente. 